\title{
Critical Entanglement: Research on Culturally and Linguistically Diverse Parental Involvement in Special Education 2000-2010
}

\author{
Cam Cobb \\ University of Windsor
}

\begin{abstract}
If parental involvement in a child's education is generally viewed in positive terms, then it is important to understand what sorts of barriers might hinder it. This article reviews literature on culturally and linguistically diverse parental involvement in special education in the United States and Canada. In analyzing 20 articles published in eight prominent journals between 2000 and 2010, the author considers what research has to say about what influences culturally and linguistically diverse parental involvement. Applying the lens of social-cultural capital led the author to examine three core themes in the literature, namely perceptions, people, and systems. Because these three themes interlock so tightly, the author devised the overarching metaphor of critical entanglement, which is vital to the process of recognizing and addressing barriers that culturally and linguistically diverse parents potentially face. Implications for research are discussed in the recommendation and conclusion segments of this article.
\end{abstract}

Much has been written about parental involvement, and a substantial amount of this literature indicates that parent-school collaboration enriches learning (Cox, 2005; Fan \& Chen, 2001; Jeynes, 2005, 2007). While some researchers have drawn attention to the transactional nature of parent-school relations (e.g., Odom et al., 2004), others have described the deepening roots of parental involvement in research, policy, and legislation (i.e., Epstein, 2001; Nisbet, Covert, \& Schuh, 1992; Osher \& Osher, 2002; Trainor, 2010a). Epstein (2001) has led many to perceive involvement in relation to different parental roles, including supporting children's participation in schooling, communicating with schools as needed, volunteering, supervising and/or assisting in homework, participating in school-based committees, and serving as a liaison between the school and community (Harry, 2008). While parental involvement is widely recognized as an important dimension of education, a variety of barriers hinders the potential for collaboration (Hornby \& Lafaele, 2011). In recent years, researchers focusing on this aspect of education have delved into the perspectives and experiences of culturally and linguistically diverse (CLD) par- 
ents as they navigate their way through complex systemic networks of special education (e.g., Cobb, 2012), and it is from this body of literature that this review draws.

Applying the lens of social-cultural capital, the author aimed to address the following questions in this review of the literature: (a) What has been written about CLD parental involvement in special education in recent years? (b) What sorts of patterns arise in this literature? and (c) What are the implications of these patterns? It is important to address these three questions because although special education legislation in Canada and the United States has deepened parental rights and opportunities to contribute to decision-making processes over the past two decades (Bowlby, Peters, \& Mackinnon, 2010; Crockett, 2007), issues of exclusion persist (Cobb, 2012; Trainor, 2010a, 2010b). By identifying the challenges associated with CLD parental involvement as they have arisen-whether tangentially or directly - in a range of studies published between 2000 and 2010, this literature review adds a comprehensive overview of social justice-oriented special education literature. While most of the studies examined in this review were conducted in the United States, the increasingly diverse nature of the world makes its findings internationally pertinent.

In quantum physics, entanglement describes the link between objects, where even the act of measuring one alters the state of the other (White, 2005). Critical entanglement, which the author extends from quantum entanglement and critical theory (Lincoln, 2010), is used as a metaphor throughout this paper because it captures the relational and multidimensional nature of parent-school interactions, whatever those interactions might involve. In the case of parental involvement in special education, the three interconnected dimensions are the perceptions people hold, the relationships people have, and the systems people encounter. It is important to examine what research has to say about CLD parental involvement with entanglement in mind because this process can lead researchers, policymakers, and practitioners to better recognize and respond to exclusionary forces that should neither be seen nor treated as separate entities.

\section{Theoretical Framework}

Underpinning this paper's core metaphor of critical entanglement is the lens of socialcultural capital. Social-cultural capital was used as a lens to explore the three core questions this study aimed to address. Social-cultural capital provides a useful way of understanding how perceived differences, at times, lead to situations of dis/advantage in society. Difference, a relational concept, is socially constructed by a variety of forces, including beliefs, values, political views, and perceptions of the past (Klingner, Artiles, \& Barletta, 2006; Minow, 1990). Views of difference, along with interlocking systems of power, influence the ways in which people interact. Ethno-race, ethno-culture, economic status, education, perceived dis/ability, sex, sexual orientation, gender, and profession are but nine aspects of identification that influence perceived differences and power relations.

For Bourdieu (1985), the relationship between perceived differences and social interplay is one that deserves close attention. He used the terms social capital and cultural capital to explain familial and social processes of interacting, and this lens led him to detail how people come to encounter layers of dis/advantage in society. According to Portes (1998), "Bourdieu's definition makes clear that social capital is decomposable into two elements: first, the social relationship itself that allows individuals to claim access to resources possessed by their associates, and second, the amount and quality of those resources" (p. 3-4). In this context, the term resource, like capital, is used metaphorically. A resource could be a physical object (e.g., an automobile), but it could also be a piece of information, a manner of communicating, or a point of view. 
When considering special education, parents' resources could be interpreted as physical objects, such as their books about child psychology or assistive technology on a home computer. A parent's resources could also be identified in less tangible ways. Parental resources could also be seen as one's awareness and/or views of special education knowledge, language, and philosophy (see Cobb, 2012). To varying degrees these views will converge or diverge from the views held by school professionals as well as systemic forces. Ultimately, the knowledges, languages, and philosophies of which people are aware and give credence to will influence the ways they are positioned in, and by, social contexts, such as parent-school exchanges. It is this less tangible aspect of parental resources that the author will analyze in this paper (see Figure 1).

Reflecting on the intersection between resources, identity and privilege has led many to draw attention to various social reproductive aspects of schools that preserve and/or intensify wider social inequities (Apple, 1986; Bowles \& Gintis, 1976; Dei, 1996; Giroux, 1983). In the past two decades, a number of researchers have applied overlapping lenses of social and cultural capital-lenses at times defined and used in different ways - to illuminate social justice issues in special education (Ong-Dean, 2009; Stanton-Salazar \& Dornbusch, 1995; Trainor, 2008, 2010a, 2010b). While critical entanglement provides a useful way of describing the relational nature of parent-school interactions, Bourdieu's (1985) theory of social-cultural capital explains why numerous systemic barriers hinder CLD parental inclusion in special education processes, and more importantly, how those barriers might be countered.

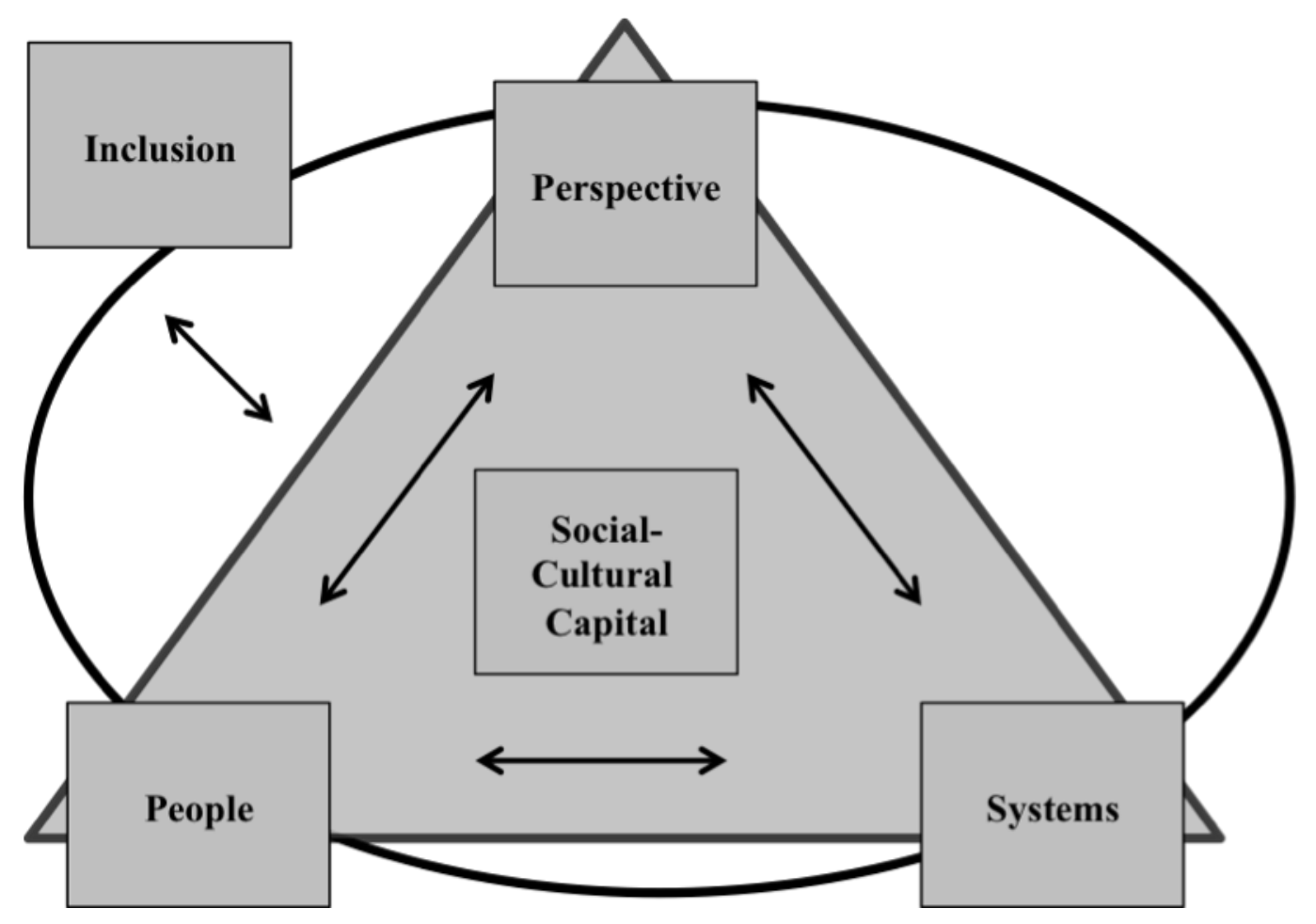

Figure 1. CLD Parental Inclusion in Special Education. 


\section{Methodology}

\section{Selection Criteria}

The primary criteria for including journal articles in this literature review was that they focus on aspects of CLD parental involvement in special education processes in Canada and/or the United States. Consequently, the eight journals used in this study are all based in the two countries. While each journal was chosen based on its subject area and circulation total, each article was chosen based on its core topic and timeline. The four above-mentioned criteria for selecting the journals and articles draw from methodological designs of numerous previously conducted meta-analyses (see Mastropieri et al., 2009; Scruggs, Mastropieri, \& McDuffie, 2007).

Journals included in this literature review were selected partly based on their different subject areas to ensure that the sample matched the core topic of this study and was representative of the field. The challenges CLD parents face in the realm of special education relate to a variety of exceptionalities (Ong-Dean, 2009). Five of the journals used in this review explore general special education topics, including Exceptional Children (EC), Journal of Special Education (JSE), Remedial and Special Education (RASE), Exceptionality (E), and Exceptionality Education International (EEI; which, prior to 2009 was entitled Exceptionality Education Canada or EEC). Because Learning Disability (LD) is the most prolific exceptionality, nearly half of the students receiving special education services in the United States have LD (U.S. Department of Education, Office of Special Education and Rehabilitative Services, Office of Special Education, 2005), the author also drew from two LD-focused journals, the Journal of Learning Disabilities $(J L D)$ and Learning Disability Quarterly $(L D Q)$. Additionally, because linguistic diversity marks a key component of social-cultural capital and the barriers that parents face (Lai \& Ishiyama, 2004; Tellier-Robinson, 2000), the author also used a prominent journal that focuses on language politics, entitled Bilingual Research Journal (BRJ).

The author sought to use journals that would provide this review with a widespread readership, and consequently the eight journals were also chosen based on their circulation totals. Urlichs' website (http://www.ulrichsweb.com/) revealed the following circulation totals for five of the journals targeted in this review: EC (42,825), JSE (3600), RASE (1700), JLD (4100), and $L D Q$ (3500; see also Mastropieri et al., 2009). The membership of the National Association for Bilingual Education, which publishes BRJ, totals 5000 (http://www.nabe.org/index.html). EEI has functioned as an online journal since it transformed from $E E C$. This literature review thus draws from a total circulation exceeding 60000.

In terms of subject matter, articles chosen for this literature review had to focus on aspects of CLD parental involvement in special education processes. When setting the timeline parameters of this review, the author considered the matters of special education legislation and change. Special education saw significant readjustment in both the United States and Canada in the late 1990s and early 2000s. In the United States, this change was evident in the 1997 Amendments to the Education for All Handicapped Children Act of 1975, the No Child Left Behind Act of 2001, and the Individuals with Disabilities Education Improvement Act of 2004 (Lashley, 2007). As Crockett (2007) pointed out, the era of statutory changes posed "higher expectations for administrators to build trust and negotiate conflicts as they participate with parents and other professionals in the delivery of special education" (p. 140). During this same period, Canadian jurisdictions, such as Ontario, made noticeable adjustments to special education regulations and policies. Regulation 181/98, for instance, required Ontario school boards to develop and make available special education guides to parents across the province (Bowlby et al., 2010). In issuing 
a new policy document in the fall of 2000, Ontario's Ministry of Education mapped out specific requirements for a school board's Special Education Plan and detailed the standards against which these plans would be measured (Bowlby et al., 2010). Because the above-mentioned changes set out, in part, to enrich parental involvement in special education, the author has focused this literature review on research published during this period of transition, between 2000 and 2010.

\section{Survey of Abstracts}

While search engines can be used effectively to narrow a vast article/journal pool (Waitoller, Artiles, \& Cheney, 2010), conducting an abstract-by-abstract survey of a smaller journal pool offers the benefit of directly reading a part of each article within the geographic and temporal parameters of the review (Hosp \& Reschly, 2003). In conducting an abstract-by-abstract examination of the eight journals between 2000 and 2010, the author identified 20 articles that explored the intersection of CLD, parental involvement, and special education (see Table 1). The journals investigated in this study are represented in the articles as follows: EC (6), RASE (6), $J S E$ (4), JLD (2), and BRJ (2). While EEI, E, and $L D Q$ published a number of studies on the subject of parental involvement (e.g., Duquette et al., 2002; Kauffman \& Hallahan, 2009; Lardieri, Blacher, \& Swanson, 2000; Wilkerson, Sherwood-Puzzello, Perry, \& Hadadian, 2001), none set out to specifically explore CLD parental experiences.

\section{Data Coding and Analysis}

Coding and analyzing data gathered from the 20 journal articles included in this review involved three steps. First, methodological aspects of the studies were noted. In a general sense, while four of the articles were literature reviews, 16 were research studies (see Table 1). Of the 16 research studies, 13 were qualitative and 3 were quantitative. Second, the participant pools of the studies were divided into five categories: (a) African-American, (b) Asian-Canadian, (c) Latin-American, (d) Portuguese-American, and (e) varied CLD experiences (see Table 2).

Table 1

Article Pool: Methodologies and Participant Totals

\begin{tabular}{|c|c|c|c|c|c|}
\hline Author(s) & Date & $\begin{array}{c}\text { Lit. } \\
\text { Review }\end{array}$ & Quantitative & Qualitative & $\begin{array}{l}\text { Number of } \\
\text { Participants }\end{array}$ \\
\hline Blue-Banning, Simmers, Frankland, Nelson, \& Beegle & 2004 & & & $\sqrt{ }$ & 137 \\
\hline Brandon, Higgins, Pierce, Tandy, \& Sileo & 2010 & & $\sqrt{ }$ & & 421 \\
\hline Butera & 2005 & & & $\sqrt{ }$ & 1 \\
\hline Ferguson & 2002 & $\sqrt{ }$ & & & N/A \\
\hline Garcia, Méndez Pérez, \& Ortiz & 2000 & & & $\sqrt{ }$ & 7 \\
\hline Geenen, Powers, \& Lopez-Vasquez & 2001 & & $\sqrt{ }$ & & 308 \\
\hline Harry & 2002 & $\sqrt{ }$ & & & $\mathrm{N} / \mathrm{A}$ \\
\hline Harry & 2008 & $\sqrt{ }$ & & & $\mathrm{N} / \mathrm{A}$ \\
\hline Harry, Klingner, \& Hart & 2005 & & & $\sqrt{ }$ & 3 \\
\hline Kozleski et al. & 2008 & & & $\sqrt{ }$ & 27 \\
\hline Kummerer \& Lopez-Reyna & 2007 & & & $\sqrt{ }$ & 3 \\
\hline Lai \& Ishiyama & 2006 & & & $\sqrt{ }$ & 10 \\
\hline Monzó & 2005 & & & $\sqrt{ }$ & 3 \\
\hline Nelson, Summers, \& Turnbull & 2010 & & & $\sqrt{ }$ & 107 \\
\hline Raspa et al. & 2005 & & $\sqrt{ }$ & & 2849 \\
\hline Rueda, Monzo, Shapiro, Gomez, \& Blacher & 2005 & & & $\sqrt{ }$ & 16 \\
\hline Tellier-Robinson & 2000 & & & $\sqrt{ }$ & 9 \\
\hline Trainor & 2005 & & & $\sqrt{ }$ & 17 \\
\hline Trainor & 2008 & $\sqrt{ }$ & & & $\mathrm{N} / \mathrm{A}$ \\
\hline Trainor & $2010 \mathrm{~b}$ & & & $\sqrt{ }$ & 33 \\
\hline
\end{tabular}


Table 2

Article Pool: Participants

\begin{tabular}{|c|c|c|c|c|c|c|c|}
\hline Author(s) & Date & $\begin{array}{c}\text { Lit. } \\
\text { Review }\end{array}$ & $\begin{array}{c}\text { African } \\
\text { American }\end{array}$ & $\begin{array}{c}\text { Asian } \\
\text { Canadian }\end{array}$ & $\begin{array}{c}\text { Latin } \\
\text { American }\end{array}$ & $\begin{array}{l}\text { Portuguese } \\
\text { American }\end{array}$ & $\begin{array}{l}\text { Varied CLD } \\
\text { Experiences }\end{array}$ \\
\hline Blue-Banning, Simmers, Frankland, & 2004 & & & & & & $\sqrt{ }$ \\
\hline $\begin{array}{l}\text { Brandon, Higgins, Pierce, } \\
\text { Tandy \& Sileo }\end{array}$ & 2010 & & $\sqrt{ }$ & & & & \\
\hline Butera & 2005 & & $\sqrt{ }$ & & & & \\
\hline Ferguson & 2002 & $\sqrt{ }$ & & & & & \\
\hline Garcia, Méndez Pérez, \& Ortiz & 2000 & & & & $\sqrt{ }$ & & \\
\hline Geenen, Powers, \& Lopez-Vasquez & 2001 & & & & & & $\sqrt{ }$ \\
\hline Harry & 2002 & $\sqrt{ }$ & & & & & \\
\hline Harry & 2008 & $\sqrt{ }$ & & & & & \\
\hline Harry, Klingner, \& Hart & 2005 & & $\sqrt{ }$ & & & & \\
\hline Kozleski et al. & 2008 & & & & & & $\sqrt{ }$ \\
\hline Kummerer \& Lopez-Reyna & 2007 & & & & $\sqrt{ }$ & & \\
\hline Lai \& Ishiyama & 2006 & & & $\sqrt{ }$ & & & \\
\hline Monzó & 2005 & & & & $\sqrt{ }$ & & \\
\hline Nelson, Summers, \& Turnbull & 2010 & & & & & & $\sqrt{ }$ \\
\hline Raspa et al. & 2005 & & & & & & $\sqrt{ }$ \\
\hline Rueda, Monzo, Shapiro, Gomez, \& & 2005 & & & & $\sqrt{ }$ & & \\
\hline Blacher & & & & & & & \\
\hline Tellier-Robinson & 2000 & & & & & $\sqrt{ }$ & \\
\hline Trainor & 2005 & & & & & & $\sqrt{ }$ \\
\hline Trainor & 2008 & $\sqrt{ }$ & & & & & \\
\hline Trainor & $2010 \mathrm{~b}$ & & & & & & $\sqrt{ }$ \\
\hline
\end{tabular}

Third, a lens of social-cultural capital was applied to guide a comparative reading of each of the 20 studies and identify patterns in CLD parental inclusion. This process indicated that barriers tend to link to three interlocking categories: perceptions, people, and systems (see Figure 1). Simply put, CLD parents' perceptions can impact on their interactions with others (e.g., school personnel), and these interactions in turn can influence how parents experience systemic processes (e.g., meetings). In considering these dimensions of inclusion, additional questions guided the author's readings of each study: How are CLD parental perceptions formed and how do those perceptions influence their personal interactions with school professionals? How do the positions and/or actions of people, such as parents and school personnel, shape the inclusion of CLD parents in special education systemic processes? and How do special education systemic processes themselves respond to perspectives and people, and contribute to CLD parental inclusion?

When exploring the above-listed questions, six subcategories arose: (a) parental views of dis/ability and/or special education system, (b) parental awareness and/or use of special education language, (c) mode and manner of communication, (d) views of parental responsibilities and/or roles, (e) views of childcare, and (f) school professionals' view of parents. These six subcategories indicate that - whether they spoke about it directly or not - many of the researchers examined in this review identified elements of social-cultural capital when outlining how parents come to experience barriers to inclusion in special education.

\section{The Literature}

The 20 articles in this journal pool were divided into groupings: (a) African-American, (b) Asian-Canadian, (c) Latin-American, (d) Portuguese-American, (e) varied CLD experiences, and (f) literature reviews. While ethno-cultural and ethno-racial groups are themselves diverse, and hold neither universal nor static views, different CLD groups face similar systemic barriers in North American society. Organizing a review in this way highlights patterns that exist in terms of challenges that CLD parents face when interacting with a systemic special education network. 
Table 3

Article Pool: Subcategories

\begin{tabular}{|c|c|c|c|c|c|c|c|}
\hline Author(s) & Date & $\begin{array}{l}\text { Parental } \\
\text { views of } \\
\text { dis/ability } \\
\text { and/or } \\
\text { special } \\
\text { education }\end{array}$ & $\begin{array}{l}\text { Parental } \\
\text { awareness } \\
\text { and/or use } \\
\text { of special } \\
\text { education } \\
\text { language }\end{array}$ & $\begin{array}{l}\text { Mode and } \\
\text { manner of } \\
\text { communication }\end{array}$ & $\begin{array}{l}\text { Views of } \\
\text { parental } \\
\text { responsibility } \\
\text { and/or role }\end{array}$ & $\begin{array}{l}\text { Views of } \\
\text { childcare }\end{array}$ & $\begin{array}{l}\text { School } \\
\text { professionals' } \\
\text { view of } \\
\text { parents }\end{array}$ \\
\hline $\begin{array}{l}\text { Blue-Banning, Simmers, } \\
\text { Frankland, Nelson, \& } \\
\text { Beegle }\end{array}$ & 2004 & $\sqrt{ }$ & & $\sqrt{ }$ & $\sqrt{ }$ & $\sqrt{ }$ & $\sqrt{ }$ \\
\hline $\begin{array}{l}\text { Brandon, Higgins, } \\
\text { Pierce, Tandy, \& Sileo }\end{array}$ & 2010 & $\sqrt{ }$ & & $\sqrt{ }$ & $\sqrt{ }$ & & \\
\hline Butera & 2005 & $\sqrt{ }$ & $\sqrt{ }$ & $\sqrt{ }$ & $\sqrt{ }$ & $\sqrt{ }$ & $\sqrt{ }$ \\
\hline Ferguson & 2002 & $\sqrt{ }$ & & $\sqrt{ }$ & $\sqrt{ }$ & $\sqrt{ }$ & \\
\hline $\begin{array}{l}\text { Garcia, Méndez Pérez, } \\
\text { \& Ortiz }\end{array}$ & 2000 & $\sqrt{ }$ & $\sqrt{ }$ & $\sqrt{ }$ & $\sqrt{ }$ & $\sqrt{ }$ & $\sqrt{ }$ \\
\hline $\begin{array}{l}\text { Geenen, Powers, \& } \\
\text { Lopez-Vasquez }\end{array}$ & 2001 & $\sqrt{ }$ & & $\sqrt{ }$ & $\sqrt{ }$ & $\sqrt{ }$ & $\sqrt{ }$ \\
\hline Harry & 2002 & $\sqrt{ }$ & $\sqrt{ }$ & $\sqrt{ }$ & $\sqrt{ }$ & $\sqrt{ }$ & $\sqrt{ }$ \\
\hline Harry & 2008 & $\sqrt{ }$ & $\sqrt{ }$ & $\sqrt{ }$ & $\sqrt{ }$ & $\sqrt{ }$ & $\sqrt{ }$ \\
\hline Harry, Klingner, \& Hart & 2005 & $\sqrt{ }$ & $\sqrt{ }$ & $\sqrt{ }$ & $\sqrt{ }$ & $\sqrt{ }$ & $\sqrt{ }$ \\
\hline Kozleski et al. & 2008 & $\sqrt{ }$ & $\sqrt{ }$ & $\sqrt{ }$ & $\sqrt{ }$ & & $\sqrt{ }$ \\
\hline $\begin{array}{l}\text { Kummerer \& Lopez- } \\
\text { Reyna }\end{array}$ & 2007 & $\sqrt{ }$ & $\sqrt{ }$ & $\sqrt{ }$ & $\sqrt{ }$ & $\sqrt{ }$ & $\sqrt{ }$ \\
\hline Lai \& Ishiyama & 2006 & $\sqrt{ }$ & $\sqrt{ }$ & $\sqrt{ }$ & $\sqrt{ }$ & & $\sqrt{ }$ \\
\hline Monzó & 2005 & & & $\sqrt{ }$ & $\sqrt{ }$ & & $\sqrt{ }$ \\
\hline $\begin{array}{l}\text { Nelson, Summers, \& } \\
\text { Turnbull }\end{array}$ & 2010 & $\sqrt{ }$ & & $\sqrt{ }$ & $\sqrt{ }$ & $\sqrt{ }$ & $\sqrt{ }$ \\
\hline Raspa et al. & 2005 & $\sqrt{ }$ & & $\sqrt{ }$ & $\sqrt{ }$ & $\sqrt{ }$ & \\
\hline $\begin{array}{l}\text { Rueda, Monzo, Shapiro, } \\
\text { Gomez, \& Blacher }\end{array}$ & 2005 & $\sqrt{ }$ & $\sqrt{ }$ & $\sqrt{ }$ & $\sqrt{ }$ & $\sqrt{ }$ & $\sqrt{ }$ \\
\hline Tellier-Robinson & 2000 & $\sqrt{ }$ & $\sqrt{ }$ & $\sqrt{ }$ & $\sqrt{ }$ & $\sqrt{ }$ & $\sqrt{ }$ \\
\hline Trainor & 2005 & $\sqrt{ }$ & $\sqrt{ }$ & $\sqrt{ }$ & $\sqrt{ }$ & & $\sqrt{ }$ \\
\hline Trainor & 2008 & $\sqrt{ }$ & $\sqrt{ }$ & $\sqrt{ }$ & $\sqrt{ }$ & & $\sqrt{ }$ \\
\hline Trainor & $2010 b$ & $\sqrt{ }$ & $\sqrt{ }$ & $\sqrt{ }$ & $\sqrt{ }$ & & \\
\hline
\end{tabular}

\section{African-American}

While three studies in this literature review focused solely on the experiences of AfricanAmerican families (i.e., Brandon, Higgins, Pierce, Tandy, \& Sileo, 2010; Butera, 2005; Harry, Klingner, \& Hart, 2005), not one explored the perspectives of African-Canadian parents. In all three studies, communication arose as a barrier for parents.

When conducting a survey with 421 African-American parents "to determine the degree of alienation, if any, that African-American parents feel toward public education" (Brandon et al., 2010, p. 208), Brandon et al. (2010) found that parents identified logistical complications and personal concerns as being the greatest problems affecting their interactions with school personnel. Personal concerns also arose in a study conducted by Harry et al. (2005). In outlining three cases drawn from an ethnographic research study of special education placement process in a diverse urban school district, Harry et al. noted, "school personnel really knew very little about the families they described in the most derogatory terms" (p. 106). More specifically, they noted that the views of school personnel often drew from fragments of information where specific facts were "taken out of context to construct portraits of family identities that were far from the truth" (Harry et al., 2005, p. 106). The deficit perception, held by school personnel involved in the study, was fed by "widespread stereotypes about Black families in inner-city neighborhoods" (Harry et al., 2005, p. 110).

Butera (2005) oversaw a case study to examine the relations between the family of Cassie, a 4-year old girl of mixed European- and African-American heritage in Appalachia, and school 
professionals. On the matter of timelines, Butera noted, "interviews with school professionals about their collaboration with Cassie's family are replete with stories of the difficulties they have had finding time to communicate" (p. 111). Time availability could be seen as an example of social-cultural capital. If a school requires a parent to meet at certain times that do not coincide with the parent's time availability, then parental involvement will be hindered. In considering the aspect of communication, Butera pointed out that rather than becoming a dialogue, one Individual Education Plan (IEP) meeting was "dominated by school administrators" (p. 115). In these two situations, time availability and communication, both factors of social-cultural capital, posed barriers for Cassie's family as they sought to collaborate and engage in shared decision-making.

\section{Asian-Canadian}

While none of the 20 studies in this review explored Asian-American parental involvement, one did examine Asian-Canadian experiences (i.e., Lai \& Ishiyama, 2004). Lai and Ishiyama (2004) conducted a qualitative study with 10 recently immigrated Chinese-Canadian mothers of children with disabilities to learn about their involvement in their children's education. Issues of communication and power arose as central themes in the study. After attempting "to share her experiences and ideas with her son's teachers," for instance, one mother "felt disappointed that the teachers displayed no interest in the educational practices of the countries where immigrant students and their families came from" (Lai \& Ishiyama, 2004, p. 104). In neglecting to acknowledge, or tap into, this mother's divergent knowledge base and point of view, it would seem that educators did not value her social-cultural capital. Ultimately, in meetings, the mothers involved in this study reported listening to school personnel and feeling uncomfortable leading conversations and articulating their views of their children's needs.

\section{Latin-American}

Four studies in this literature review focused solely on the Latin-American community (i.e., Garcia, Méndez Pérez, \& Ortiz, 2000; Kummerer \& Lopez-Reyna, 2009; Monzó, 2005; Rueda, Monzo, Shapiro, Gomez, \& Blacher, 2005). Power imbalance, communication issues, and a sharp disconnect between the perspectives of schools and parents arose as key themes in the studies. Focusing on the placement of children in bilingual programs led Monzó (2005) to identify situations where eight Latino parents were given limited choice regarding program delivery. In one case, a mother was not only excluded from decision-making processes relating to her child's placement, but had been misled by the wording of school documents. The confusing language of the documents prompted the mother to believe that her daughter had been placed in a bilingual classroom, as she had hoped. Monzó's 2-year ethnographic study revealed that parents did not always understand information provided by school professionals, and some were reluctant to ask the school for assistance and/or oppose school decisions regarding placement. Awareness of special education language and procedures, positioning, and linguistic miscommunication formed barriers for the families.

The power imbalance associated with positioning and institutional authority arose as a theme when Kummerer and Lopez-Reyna (2009) delved into the lives and experiences of three immigrant Mexican-American mothers and their children. The families involved in this study spoke about their experiences participating in early intervention speech-language therapy. According to the researchers, perceptions of status prompted the mothers to feel reluctant to offer suggestions regarding their child's learning program even in situations where they felt anxious and had strong views. 
Divergence formed a key theme for Garcia et al. (2000) and Rueda et al. (2005). In examining Mexican-American mothers' beliefs about language disabilities from a socio-cultural perspective, the researchers observed that "the mothers participating in the study did not believe that their children had communication disorders, nor were they concerned about the children's language development in relation to expected milestones" (Garcia et al., p. 92-93). Possible reasons for this disagreement, according to the research team, included differing connotations of the terms used by school professionals and communication breakdowns between the two groups.

While Rueda et al. (2005) explored a different aspect of special education - the transition into adulthood - diverging perspectives once again arose as a major theme in the study. Conducting focus groups with 16 Latina mothers of young adults with disabilities enabled the research team to examine culturally based variations in parental attitudes, beliefs, and meanings of transition. The research team identified ways in which parental views differed from those of school professionals in relation to basic life skills and social adaptation, the importance of the mothers' role and expertise in decision-making, and the dangers of the outside world. "What was striking to us," Rueda et al. (2005) noted, "was the lack of a shared perspective between these mothers and the system designed to help them and their children" (p. 411).

The four studies examined in this subsection indicate that when Latin-American parental perceptions of knowledge, language and philosophy, which themselves are varied, differ from systemic special education concepts and processes, they function as barriers which diminish the position and inclusion of parents in special education processes.

\section{Portuguese-American}

One study, led by Tellier-Robinson (2000), investigated the involvement of Portuguesespeaking parents in the education of their special needs children. Tellier-Robinson applied ethnographic interviewing and participant observation to draw from nine families, and noted that parents "spoke with some annoyance and resentment of the extent to which they had to fight for what they thought was due their children" (p. 316). Rather than learning about and/or utilizing the resources these families offered, school professionals tended to downplay their involvement. This was unfortunate because the parents "had a great deal of knowledge about their own culture in addition to the skills of their various professions and occupations" (Tellier-Robinson, 2000, p. 320). To become more involved in special education processes, the parents in this study researched and taught themselves about their rights, as well as services available to them and their children. The families cited a lack of awareness of special education procedures and rights as barriers to their inclusion. As with the studies focusing on African-American experiences, school professionals held a deficit view of the perspectives and actions of these families, which fostered an atmosphere of parental exclusion.

\section{Varied CLD Experiences}

Eight studies in this literature review considered varied CLD experiences, and some important findings that came out of these studies related to knowledge, systemic and interpersonal power imbalances, and issues associated with perspective and communication. In these eight studies of varied CLD parental contexts, social-cultural capital arose repeatedly as a barrier.

In 2001, Geenen, Powers, and Lopez-Vasquez surveyed 308 African-American, HispanicAmerican, Native-American, and European-American parents to better understand how CLD parent communities access, participate in, and conceptualize transition-planning activities. The study identified a variety of barriers that are intensified for CLD parents: (a) lack of parental 
knowledge about their rights, school procedures, or policies; (b) rigid or limited options for parental involvement in educational planning; and (c) issues associated with power imbalance.

Blue-Banning, Simmers, Frankland, Nelson, and Beegle (2004) applied qualitative inquiry with 33 focus groups and 32 individual interviews with non-English-speaking parents to ask: What are the key indicators of professional behaviour facilitative of collaborative partnerships? For parents, tact, or manner of communication conveyed by school professionals was important. Also, parents pointed out that access to information about different sorts of special education resources was a problem that needed to be addressed: "participants in several focus group sessions described multiple times when they had 'stumbled' on information they thought was critical for their child" (Blue-Banning et al., 2004, p. 175). School professionals, according to the researchers' findings, need to acknowledge the validity of parental views before they can respond effectively and respectfully to linguistically diverse parents. Nelson, Summers, and Turnbull (2004) drew from 34 focus groups and 32 individual interviews when asking: How do parents and school professionals view the closeness of their relationship, which at times involves assuming multiple roles? Communication formed a key barrier in the study, as "cultural values directly influenced the extent to which parents expect to have formal versus informal, hierarchical versus egalitarian, and distant versus close relationships" (Nelson et al., 2004, p. 163).

In a 2005 study, Trainor asked, What are different self-determination perceptions and behaviours of European-American, African-American, and Hispanic-American male adolescents with LD? Participants in the study felt uninvolved in their transition planning processes where mismatch between exit goals and student interview responses led to communication and larger systemic issues (Trainor, 2005). When gathering qualitative data from 15 Hispanic parents, 10 African-American parents, and 2 White parents, Kozleski et al. (2008) asked, How do elements of context and culture shape the ways in which different families access and experience special education processes when their children have disabilities? Identifying a relationship between power imbalances and issues with communication, Kozleski et al. noted that a perception of families as recipients subordinated their role, or position, and legitimized the practice of using poor or nonexistent communication. A large-scale quantitative study (i.e., Raspa et al., 2010) utilized Family Outcomes Survey data to ask, What are the dimensions of diversity in relation to early intervention? Raspa et al. (2010) ultimately found that "early intervention may have two distinct components - one related to a more traditional view of services (e.g., rights, therapies, assessments, interventions) and one related to social supports and community access" (p. 508509). Because parental involvement is a foundation of any special education system, communication and collaboration need to be organized around-and rooted in-culturally responsive practice (Trainor, 2010b).

\section{Literature Reviews}

In addition to the above-described 16 research studies, four literature reviews fell within the parameters of the selection criteria (i.e., Ferguson, 2002; Harry, 2002, 2008; Trainor, 2008). When examining the research on parental reactions to having a child with a disability, Ferguson (2002) noted that the neglect to consider cultural and generational variables contributes to gaps in family and disability-oriented literature. Of the situation, he stated that "until recently, most research on families of children with disabilities tended to gloss over the situation complexities and cultural variabilities that surround all of us" (Ferguson, 2002, p. 129). Conducting a literature review on postsecondary outcomes and transition planning led Trainor (2008) to argue that school professionals need to respect and value youths' social-cultural capital in order to push be- 
yond superficial levels of acquaintance. Two years later, she applied the lens of social-cultural capital to examine diverse approaches to parent advocacy in a qualitative study (Trainor, 2010b).

When reviewing trends and issues in serving culturally diverse families of children with disabilities, Harry (2002) observed that although there is a large - and growing — body of research dedicated to the topic of culturally responsive practice, the question of support, which itself is an old question, continues to lack a clear and cohesive answer. Six years later, Harry (2008) reviewed literature that offers definitions of collaborative interactions and relationships between CLD parents and school personnel. In summarizing her findings, she noted that "three decades of literature on the involvement of CLD families in the special education process underscores the continuing challenge of collaboration across perceived barriers of race, culture, language, and social class" (Harry, 2008, p. 385). It is unfortunate, but this call for reciprocity between schools and CLD communities is still relevant today.

\section{Summary}

As the 20 studies in this literature review indicate, CLD parents face a variety of barriers that hinder their involvement in special education, including divergent perspectives, power imbalances, and knowledge of systemic processes and/or rights. The following segment outlines the author's interpretation of these themes and details a series of thematically clustered recommendations.

\section{Discussion}

Analyzing the findings of the 20 studies included in this review reveals that CLD parental involvement tends to fall into three entangled areas: perceptions, people, and systems. This discussion includes a description of these themes, each followed by a series of recommendations. While the interconnected nature of the three dimensions, as well as their associated recommendations, indicates a relationship of critical entanglement, the dynamics of power and privilege that undercut all three highlight the pervasive nature of social-cultural capital.

\section{Perceptions}

Perception, which is entangled with people and systems, is the way in which individuals view and define what surrounds them. But how are CLD parental perceptions formed and how do those perceptions influence their personal interactions with school professionals? Parents and school professionals, at times, view dis/ability, childcare, special education services, and special education language in different ways. They also, on occasion, view their own as well as one another's responsibilities and roles in different ways. It is important to pay attention to this dimension of special education because perceptions not only inform the actions of people, but they also inform how people interpret the actions of others. In the literature analyzed in this review, perception, which could be viewed as a resource through a social-cultural capital lens, arose as a profound aspect of CLD parent experiences. But how exactly does perception affect CLD parental involvement?

According to the majority of studies examined in this review, the way in which school personnel responded to CLD parental perspectives adversely affected parental inclusion. For instance, when CLD parents' perceptions of what constitutes responsible, or even acceptable, lifestyle choices (e.g., child care arrangements), school professionals-who held conflicting views - viewed and treated the parents with distain and/or disrespect (Garcia et al., 2000; Harry, 
2008; Harry et al., 2005; Kummerer \& Lopez-Reyna, 2009). Similarly, when CLD parents involved themselves in their child's education in ways that fell outside the bounds of definitions held by school professionals, parental involvement was perceived as minimal or not even acknowledged (Butera, 2005; Kozleski et al., 2008; Kummerer \& Lopez-Reyna, 2009; Lai \& Ishiyama, 2004; Rueda et al., 2005; Trainor, 2010b). In situations where perception led CLD parents to elevate the role, or status, of school professionals, those parents tended to refrain from voicing their concerns in interviews and at meetings, despite their concerns (see, for example, Lai \& Ishiyama, 2004; Monzó, 2005). As these contexts unfolded, parents did not expect schools to seek out, or even desire, collaboration (Kummerer \& Lopez-Reyna, 2009; Lai \& Ishiyama, 2004; Monzó, 2005; Rueda et al., 2005).

Special education awareness (i.e., of services and terminology) is another important aspect of perception. For instance, when CLD parents were unaware of their rights, as well as the rights of their children, they were less likely to access or actively interact with supports they needed, such as interpretation and/or translation services (Kozleski et al., 2008; Kummerer \& LopezReyna, 2009; Tellier-Robinson, 2000). While perception can potentially act as a barrier, diverging perspectives may even lead school professionals to hold deficit views of CLD parents. Because perception influences, and is influenced by, the ways in which people view and interact with one another, as well as with larger systems themselves, perception is entangled with people and systems.

\section{Perceptions-Oriented Recommendations}

Perception is a matter of awareness and respect. Before school professionals can foster a robust form of reciprocity through CLD parental involvement in the realm of special education, they need to accept that perceptions may differ. Further, they need to understand those different perspectives, or forms of social-cultural capital, of the parents with whom they interact and ultimately incorporate that understanding into the ways in which they foster collaboration. Future research needs to examine contexts where school professionals in the special education realm seek out and respond to divergent views within school communities. It would also be beneficial to study ways in which pre-service education as well as ongoing professional development programs prepare educators in this regard. A key aim should be to prepare school professionals to create opportunities for the exchange of ideas (i.e., when identifying learning needs and developing learning plans) and foster rich dialogue and collaboration with parents in a variety of situations, such as IEP meetings, staff meetings, and school council meetings.

\section{People}

Because one's perceptions ultimately influence her/his interactions with others, the second core theme explored in this literature review is people. In considering the aspect of people, it is necessary to ask, How do the positions and/or actions of people, such as parents and school personnel, shape the inclusion of CLD parents in special education systemic processes?

Special education, like education in general, involves many situations where parents and school professionals interact both formally and informally. Special education procedures, such as the development of a child's IEP, involve ongoing verbal exchanges as well as written documentation. The perceptions held by parents and school professionals can profoundly influence the sort of relationship that is formed in these interactions. When families participate in these verbal and written processes, however, extensive, and sometimes unclear, special education terminology creates barriers for CLD parents, especially for those who speak English as an additional 
language (Garcia et al., 2000; Harry et al., 2005; Kozleski et al., 2008). When school professionals use the argument by repetition strategy in interpersonal exchanges, such as interviews and IEP meetings, parents can be dissuaded from countering school-based suggestions (Butera, 2005; Kozleski et al., 2008). Different stylistic ways in which people communicate, such as tone of voice, body language, eye contact, and use of direct/indirect speech, can also foster unbalanced exchanges that diminish, or silence, the voices of CLD parents (Blue-Banning et al., 2004).

The manner in which a parent-school professional interaction unfolds can adversely influence the tone of subsequent exchanges, such as telephone conversations, the level of trust in the relationship, or lack thereof, and the power dynamic between the individuals involved in the relationship. A standardized approach to parent-school interactions would neglect to recognize a diversity of perspectives and ultimately diminish the possibility of moving verbal-written exchanges into collaborations rooted in reciprocity (Harry, 2002). When school professionals take a standardized approach to parent-school exchanges, CLD parents holding diverging perspectives face additional, or intensified, barriers. Such an approach would also fail to acknowledge that special education in North America has been founded on Euro-Western conceptions of success, intelligence, knowledge, and what constitutes acceptable behaviour (Geenen et al., 2001; Kozleski et al., 2008; Lai \& Ishiyama, 2004; Tellier-Robinson, 2000).

To counter the above-mentioned forces of disempowerment, a number of researchers ask, How do school professionals prepare themselves to foster the inclusion of CLD parents who are navigating a special education network? When school professionals actively endeavor to listen to parent perspectives and then take those perspectives into account as they schedule meetings, conduct assessments, plan lessons, differentiate instruction, and so on, they can act in ways that are not only caring but are also culturally responsive. In describing strategies for culturally responsive programming - and countering systems of social-cultural capital-many researchers have suggested ways in which divergent CLD perspectives could be recognized and ultimately treated as a resource, rather than a detriment (e.g., Butera, 2005; Harry, 2008; Kozleski et al., 2008; Rueda et al., 2005; Trainor, 2005, 2008). With a highly interactive relationship, the dimensions of perceptions and people cannot, and indeed should not, be disentangled.

\section{People-Oriented Recommendations}

The human dimension is inexorably linked to perception because it is people, such as parents, children, and school professionals, who have, and act on, perceptions. Before school professionals can foster more inclusive forms of parental involvement in special education, they need to desire, seek out, and create opportunities for CLD parents to articulate their perspectives and then collaborate in a dynamic of reciprocity. Enhancing parental involvement may be achieved in a variety of ways. First, in terms of logistics, school professionals need to establish multiple and varied opportunities and safe spaces for dialogue in settings and at times that are convenient for parents. School professionals, for instance, need to recognize that interactions with parents do not necessarily have to take place on school property within the hours of a school day. Second, when dialoguing with parents, school professionals need to listen and respond in ways that acknowledge the different manners in which parents view parent-school collaboration. Parents, for instance, need to have ample and varied opportunities to speak with educators when collaborating on the creation or revision of an IEP. Third, school professionals need to create multiple and varied opportunities for parents to review communications, decisions, and education plans for special education learners. School professionals need to use regular and multiple modes of communication, such as phone calls, face-to-face conversations, and clearly worded 
notes, to share their views with parents, engage in meaningful discussion, and collaborative planning. Further research needs to examine contexts where school professionals successfully apply the above-mentioned practices of inclusion. Such research will illuminate the interlocking matters of (a) how school professionals foster inclusion through interpersonal interactions and (b) how they come to value such a goal. The human dimension is a matter of building and nurturing personal relationships that not only respects parents but also empowers them.

\section{Systems}

Third, there is the systemic dimension, which involves the special education system itself. Parents and school professionals are not only involved in a relationship with one another, but they also interact with a larger special education organization. While both parents and school personnel are at once interpreting and constructing policy on a regular basis (Kozleski et al., 2008; Trainor, 2008), the influence of the system itself cannot be ignored. But how do special education systemic processes themselves respond to perspectives and people, and contribute to CLD parental inclusion?

When considering systemic aspects of special education, researchers examined in this literature review raised questions about systemic factors that diminish CLD parental involvement, including (a) To what extent is a standardized special education system able to serve and respond to the individual needs and views of CLD parent communities? (b) To what extent do the dominant views embedded within special education networks support or hinder CLD parental involvement (i.e., in decision-making processes)? and (c) How is reciprocity encouraged by special education systems? By privileging certain pools of knowledge, notions of intelligence, and modes of communication, systemic special education networks demand social-cultural capital in ways that act as inclusion filters, which can diminish a CLD parents' chances of becoming actively involved in their child's education (Harry et al., 2005; Kozleski et al., 2008; Trainor, 2008, 2010a, 2010b).

Many researchers have called for schools, and indeed research itself, to interrogate the social-cultural capital valuation system of special education and develop ways to counter it both at the pre-service and in-service levels (Butera, 2005; Harry, 2008; Kozleski et al., 2008; Rueda et al., 2005; Trainor, 2008). Additionally, several researchers examined in this literature review have called for school professionals to be supported in their ongoing professional development in ways that will help them to perceive and treat CLD as a community resource, rather than a deficit (i.e., Butera, 2005; Geenen et al., 2001; Harry, 2008; Kozleski et al., 2008; Lai \& Ishiyama, 2004; Rueda et al., 2005; Trainor, 2005, 2008). Because perceptions and people are so closely connected to the larger special education system itself, and because the three continually influence the form and/or experiences of one another, they are entangled.

\section{Systems-Oriented Recommendations}

The dimensions of respecting diverging perceptions, nurturing human relationships, and fostering collaboration need to be supported at the systemic level. In this way, the first two themes and recommendations are entangled with the third. First, systemic definitions of subjective concepts, such as definitions of parental involvement, need to broaden and take a multiplicity of views into account. This conceptual and linguistic shift to inclusion will help to counter deficit views of CLD parents that stem from differences of perspective. Second, school professionals, such as teachers, speech-language therapists, and school board psychologists, need to be equipped to foster robust forms of collaboration both at the pre-service and in-service lev- 
els (for a comprehensive literature review on preparing pre-service educators for cultural diversity, see Trent, Kea, \& Oh, 2008). School leaders themselves need to be prepared to develop and refine strategies that not only encourage but also nurture a school-wide practice of fostering rich forms of collaboration that acknowledges and draws from the different forms of social capital that CLD parents have to offer. In addition to deepening the insights of CLD perspectives of school professionals on a systemic level, these professionals also need to be provided with the resources, such as adequate amounts of preparation time and established partnerships with community organizations that will support them as they apply the ideas of respect, reciprocity, and empowerment in their day-to-day practices. Additional studies that examine ways in which individuals, and/or school boards, work to reduce systemic barriers that CLD parents might otherwise face need to be conducted. Such studies will highlight ways in which systemic barriers in special education can be identified as well as how they can be actively countered.

\section{Limitations}

It is important to identify the limitations of this literature review. First, there is the size of journal pool. While the eight U.S. and Canadian journals used in this review were systematically chosen, a number of informative journals were excluded, such as Autism, Journal of Autism and Developmental Disorders, and International Journal of Special Education. Second, there is the absence of Canadian content. This absence is not surprising because the seven U.S. journals used in this review would not necessarily be interested in Canadian studies, unless they were perceived as relevant to the U.S. market. Third, there is the international dimension. Because this literature review only draws from research conducted in Canada and the United States, future reviews of research need to consider what a more global pool of research says about CLD parental involvement in special education. Although this study has limitations, its findings and recommendations - as presented through the metaphor of critical entanglement - have implications for research, policy, and practice.

\section{Conclusion}

The author approached this review of the literature with three core questions in mind: (a) What has been written about CLD parental involvement in special education in recent years? (b) What sorts of patterns arise in this literature? and (c) What are the implications of these patterns? The 20 studies examined indicate CLD parents can potentially face numerous barriers linked to social-cultural capital. These barriers, which are posed by school professionals and/or systemic forces, could be connected to three interlocking realms of perceptions, people, and systems. Many of the studies in this review suggest that cultural responsive practices would lead schools to foster deeper forms of parental inclusion in the special education arena, and they also offer suggestions for change in this regard (Butera, 2005; Harry, 2008; Kozleski et al., 2008; Lai \& Ishiyama, 2004; Rueda et al., 2005; Trainor, 2005, 2008). Further research needs to identify and examine contexts where school professionals have successfully worked to foster rich forms of CLD parental inclusion. Such studies would help to understand and illustrate different ways in which school professionals come to value, understand, and practice CLD parental inclusion.

This review of the literature contributes to special education knowledge. First, in analyzing current research on the subject of CLD parental inclusion, this review identifies specific areas where further research is needed. Second, by developing the metaphor of critical entanglement this article outlines a way in which the barriers that CLD parents potentially face might be studied and countered. Reflecting on the three dimensions, and interlocking nature, of percep- 
tions, people, and systems might also assist researchers as they study different ways in which school professionals have successfully fostered CLD parental inclusion in special education. The recommendations proposed by the author are entangled and messy. While some of these recommendations have been put forward by other studies, they continue to represent necessary goals if special education is to become a more inclusive landscape. The different forms of social-cultural capital that some CLD parents possess cannot continue to diminish their involvement in special education processes. In fact, they need to be utilized. Ultimately, the author's aim in applying the lens of social-cultural capital in this literature review was not to consider whether CLD parents possess any capital, because clearly they do, but rather to identify which sorts of capital habitually get privileged. The overarching metaphor of critical entanglement is presented as a way of perceiving the complex relationship between social-cultural capital and CLD parental inclusion. If CLD parents are to feel, and actually become, more robustly included in special education, varied strategies must address the entangled dimensions of perspectives, people, and systems.

\section{References}

Apple, M. (1986). Teachers and texts: A political economy of class and gender relations in education. New York, NY: Routledge.

Blue-Banning, M., Simmers, J. A., Frankland, H. L. N., Nelson, L. L., \& Beegle, G. (2004). Dimensions of family and professional partnerships: Constructive guidelines for collaboration. Exceptional Children, 70(2), 167-184. Retrieved from http://www.cec.sped.org/Publications/CEC-Journals/ExceptionalChildren?sc_lang=en

Bourdieu, P. (1985). The forms of capital. In J. G. Richardson (Ed.), Handbook of theory and research for the sociology of education (pp. 241-258). New York, NY: Greenwood.

Bowlby, B., Peters, C., \& Mackinnon, M. (2010). An educator's guide to special education law (2nd ed.). Aurora, ON: Cartwright Group.

Bowles, S., \& Gintis, H. (1976). Schooling in capitalist America. New York, NY: Basic Books.

Brandon, R. R., Higgins, K., Pierce, T., Tandy, R., \& Sileo, N. (2010). An exploration of the alienation experienced by African American parents from their children's educational environment. Remedial and Special Education, 31(3), 208-222. doi:10.1177/0741932509338350

Butera, G. (2005). Collaboration in the context of Appalachia: The case of Cassie. Journal of Special Education, 39(2), 106-116. doi:10.1177/00224669050390020101

Cobb, C. (2012). Speed bumps, roadblocks and tollbooths: How culturally and linguistically diverse parents navigate the highways and byways of giftedness in Ontario. British Journal of Special Education, 39(1), 12-20. doi:10.1111/j.1467-8578.2012.00531.x

Cox, D. D. (2005). Evidence-based interventions using home-school collaboration. School Psychology Quarterly, 20(4), 473-497. doi:10.1521/scpq.2005.20.4.473

Crockett, J. B. (2007). The changing landscape of special education administration. Exceptionality, 15(3), 139142. doi:10.1080/09362830701503487

Dei, G. J. S. (1996). Anti-racism education. Halifax, NS: Fernwood Publishing.

Duquette, C., Durieux-Smith, A., Olds, J., Fitzpatrick, E., Eriks-Brophy, A., \& Whittingham, J. (2002). Parents' perspectives on their roles in facilitating the inclusion of their children with hearing impairment. Exceptionality Education Canada, 12(1), 19-36.

Epstein, J. L. (2001). School, family, and community partnerships: Preparing educators and improving schools. Boulder, CO: Westview Press.

Fan, X., \& Chen, M. (2001). Parent involvement and students' academic achievement: A meta-analysis. Educational Psychology Review, 13(1), 1-22. doi:10.1023/A:1009048817385

Ferguson, P. (2002). A place in the family: An historical interpretation of research on parental reactions to having a child with a disability. Journal of Special Education, 36(3), 124-131. doi:10.1177 /00224669020360030201 
Garcia, S. B., Méndez Pérez, A., \& Ortiz, A. A. (2000). Interpreting Mexican-American mothers' beliefs about language disabilities from a sociocultural perspective. Remedial and Special Education, 21(2), 90-102. doi:10.1177/074193250002100204

Geenen, S., Powers, L. E., \& Lopez-Vasquez, A. (2001). Multicultural aspects of parent involvement in transition planning. Exceptional Children, 67(2), 265-282. Retrieved from http://www.cec.sped.org /Publications/CEC-Journals/Exceptional-Children?sc_lang=en

Giroux, H. (1983). Theories of reproduction and resistance in the new sociology of education. Harvard Educational Review, 53(3), 257-293. Retrieved from http://www.hepg.org/main/her/Index.html

Harry, B. (2002). Trends and issues in serving culturally diverse families of children with disabilities. Journal of Special Education, 36(3), 132-140. doi:10.1177/00224669020360030301

Harry, B. (2008). Collaboration with culturally and linguistically diverse families: Ideal versus reality. Exceptional Children, 74(3), 372-388. Retrieved from http://www.cec.sped.org/Publications/CEC-Journals /Exceptional-Children?sc_lang=en

Harry, B., Klingner, J. K., \& Hart, J. (2005). African American families under fire: Ethnographic views of family strengths. Remedial and Special Education, 26(2), 101-112. doi:10.1177 /07419325050260020501

Hornby, G., \& Lafaele, R. (2011). Barriers to parental involvement in education: An explanatory model. Educational Review, 63(1), 37-52. doi:10.1080/00131911.2010.488049

Hosp, J. L., \& Reschly, D. J. (2004). Disproportionate representation of minority students in special education: Academic, demographic, and economic predictors. Exceptional Children, 70(2), 185-199. Retrieved from http://www.cec.sped.org/Publications/CEC-Journals/Exceptional-Children?sc lang=en

Jeynes, W. H. (2005). A meta-analysis of the relation of parental involvement to urban elementary school student academic achievement. Urban Education, 40(3), 237-269. doi:10.1177/0042085905274540

Jeynes, W. H. (2007). The relation between parental involvement and urban secondary school student academic achievement. Urban Education, 42(1), 82-110. doi:10.1177/0042085906293818

Kauffman, J. M., \& Hallahan, D. P. (2009). Parental choices and ethical dilemmas involving disabilities: Special education and the problem of deliberately chosen disabilities. Exceptionality, 17(1), 45-62. doi:10.1080/09362830802667835

Klingner, J. K., Artiles, A. J., \& Barletta, L. M. (2006). English language learners who struggle with reading: Language acquisition or LD? Journal of Learning Disabilities, 39(2), 108-128. doi:10.1177 /00222194060390020101

Kozleski, E. B., Engelbrecht, P., Hess, R., Swart, E., Eloff, I., Oswald, M.,...Jain, S. (2008). Where differences matter: A cross-cultural analysis of family voice in special education. Journal of Special Education, 42(1), 26-35. doi:10.1177/0022466907313606

Kummerer, S., \& Lopez-Reyna, N. A. (2009). Engaging Mexican immigrant families in language and literacy interventions: Three case studies. Remedial and Special Education, 30(6), 330-343. doi:10.1177 /0741932508321014

Lai, Y., \& Ishiyama, F. I. (2004). Involvement of immigrant Chinese Canadian mothers of children with disabilities. Exceptional Children, 71(1), 97-108. Retrieved from http://www.cec.sped.org/Publications /CEC-Journals/Exceptional-Children?sc_lang=en

Lardieri, L. A., Blacher, J., \& Swanson, H. L. (2000). Sibling relationships and parent stress in families of children with and without learning disabilities. Learning Disability Quarterly, 23(2), 105-116. doi: $10.2307 / 1511140$

Lashley, C. (2007). Principal leadership for special education: An ethical framework. Exceptionality, 15(3), 177-187. doi:10.1080/09362830701503511

Lincoln, Y. S. (2010). "What a long, strange trip it's been ...": Twenty-five years of qualitative and new paradigm research. Qualitative Inquiry, 16(1), 3-9. doi:10.1177/1077800409349754

Mastropieri, M., Berkeley, S., McDuffie, K. A., Graff, H., Marshak, L., Conners, N. A.,...Cuenca-Sanchez, Y. (2009). What is published in the field of special education? An analysis of 11 prominent journals. Exceptional Children, 76(1), 95-109. Retrieved from http://www.cec.sped.org/Publications/CEC-Journals /Exceptional-Children?sc_lang=en

Minow, M. (1990). Making all the difference: Inclusion, exclusion, and American law. Ithaca, NY: Cornell University Press. 
Monzó, L. D. (2005). Latino parents' “choice” for bilingual education in an urban California school: Language politics in the aftermath of Proposition 227. Bilingual Research Journal, 29(2), 365-386. doi:10.1080 /15235882.2005.10162840

Nelson, L. G. L., Summers, J. A., \& Turnbull, A. P. (2004). Boundaries in family-professional relationships: Implications for special education. Remedial and Special Education, 25(3), 153-165. doi:10.1177 /07419325040250030301

Nisbet, J., Covert, S., \& Schuh, M. (1992). Family involvement in the transition from school to adult life. In F. R. Rusch, L. DeStefano, J. Chadsey-Rusch, L. A. Phelps, \& E. Szymanski (Eds.), Transition from school to adult life: Models, linkages, and policy (pp. 408-424). Sycamore, IL: Sycamore.

Odom, S. L., Vitzhum, J., Wolery, R., Lieber, J., Sandall, S., Hanson, M. J.,...Horn, E. (2004). Preschool inclusion in the United States: A review of research from an ecological systems perspective. Journal of Research on Special Education Needs, 4(3), 17-49. doi:10.1111/J.1471-3802.2004.00016.x

Ong-Dean, C. (2009). Distinguishing disability: Parents, privilege, and special education. Chicago, IL: The University of Chicago Press.

Osher, T. W., \& Osher, D. M. (2002). The paradigm shift to true collaboration with families. Journal of Child and Family Studies, 11(1), 47-60. doi:10.1023/A:1014715527823

Portes, A. (1998). Social capital: Its origins and applications in modern sociology. Annual Review of Sociology, 24, 1-24. doi: 10.1146/annurev.soc.24.1.1

Raspa, M., Bailey Jr., D. B., Nelson, R., Robinson, N., Simpson, M. E., Guillen, C., \& Houts, R. (2010). Measuring family outcomes in early intervention: Findings from a large-scale assessment. Exceptional Children, 76(4), 496-510. Retrieved from http://www.cec.sped.org/Publications/CEC-Journals /Exceptional-Children?sc_lang=en

Rueda, R., Monzo, L., Shapiro, J., Gomez, J., \& Blacher, J. (2005). Cultural models of transition: Latina mothers of young adults with development disabilities. Exceptional Children, 71(4), 401-414. Retrieved from http://www.cec.sped.org/Publications/CEC-Journals/Exceptional-Children?sc_lang=en

Scruggs, T. E., Mastropieri, M. A., \& McDuffie, K. A. (2007). Co-teaching in inclusive classrooms: A metasynthesis of qualitative research. Exceptional Children, 73(4), 392-416. Retrieved from http://www.cec .sped.org/Publications/CEC-Journals/Exceptional-Children?sc_lang=en

Stanton-Salazar, R. D., \& Dornbusch, S. M. (1995). Social capital and the reproduction of inequality: Information networks among Mexican-origin high school students. Sociology of Education, 68(2), 116-135. doi: $10.2307 / 2112778$

Tellier-Robinson, D. (2000). Involvement of Portuguese-speaking parents in the education of their specialneeds children. Bilingual Research Journal, 24(3), 309-323. doi:10.1080/15235882.2000.10162768

Trainor, A. A. (2005). Self-determination perceptions and behaviors of diverse students with LD during the transition planning process. Journal of Learning Disabilities, 38(3), 233-249. doi:10.1177 /00222194050380030501

Trainor, A. A. (2008). Using cultural and social capital to improve postsecondary outcomes and expand transition models for youth with disabilities. Journal of Learning Disabilities, 42(3), 148-162. doi:10.1177 /0022466907313346

Trainor, A. A. (2010a). Reexamining the promise of parent participation in special education: An analysis of cultural and social capital. Anthropology and Education, 41(3), 245-263. doi:10.1111/j.1548-1492 $.2010 .01086 . x$

Trainor, A. A. (2010b). Diverse approaches to parent advocacy during special education home-school interactions: Identification and use of cultural and social capital. Remedial and Special Education, 31(1), 3447. doi:10.1177/0741932508324401

Trent, S. C., Kea, C. D., \& Oh, K. (2008). Preparing preservice educators for cultural diversity: How far have we come? Exceptional Children, 74(3), 328-350. Retrieved from http://www.cec.sped.org/Publications /CEC-Journals/Exceptional-Children?sc_lang=en

U.S. Department of Education, Office of Special Education and Rehabilitative Services, Office of Special Education. (2005). 25 th annual (2003) report to congress on the implementation of the Individuals with Disabilities Education Act, volume 1. Washington, DC: Education Publications Center, Author. 
Waitoller, F. R., Artiles, A. J., \& Cheney, D. A. (2010). The miner's canary: A review of overrepresentation research and explanations. The Journal of Special Education, 44(1), 29-49. doi:10.1177 /0022466908329226

White, M. J. (2005). A teaspoon and an open mind: The science of Doctor Who. London, UK: Allen Lane.

Wilkerson, S. A., Sherwood-Puzzello, C., Perry, D., \& Hadadian, A. (2001). Parents of infants and young children with special needs: What do they want to know? Exceptionality Education Canada,11(1), 25-38.

\section{Authors' Note}

Correspondence concerning this article should be addressed to Cam Cobb, Faculty of Education, University of Windsor, 401 Sunset Avenue, Windsor, ON, Canada, N9B 3P4.

Email: cobbcam@uwindsor.ca 